\title{
Enunciação e atitude responsiva em processos intera- tivos: construindo dialogias na Educação Infantil
}

Resumo: Este artigo aborda o problema da enunciação e a atitude responsiva na relação adulto-crianças na dinâmica dialógica da educação infantil. Para tanto estabelece interlocução entre autores do Círculo de Bakhtin, acerca da linguagem à compreensão da infância no contexto da educação infantil e os Estudos da Infância por uma perspectiva que envolve a relação entre pares, com destaque à noção de reprodução interpretativa e o conceito de ordem social instituinte, à construção das culturas infantis pelas crianças. Sob a premissa das práticas educativas que partem das interações e das brincadeiras, como situações educativas privilegiadas para observar as culturas infantis, propõe um estudo exploratório sobre a dinâmica dialógica em uma turma de Pré, de uma escola municipal de Curitiba, evidenciada em momentos de processos interativos decorrentes de uma proposta enunciada pela professora de movimento, cujas atitudes responsivas das crianças sugerem manifestações de suas culturas infantis. Esses momentos, registrados pela pesquisadora por meio da fotografia, são revisitados pela observação das imagens à interpretação das relações entre pares e relaciona percepções da vivência rememorada pela pesquisadora sobre as atitudes responsivas das crianças. Destaca-se desse estudo que observar o que as crianças realizam em suas interações e brincadeiras, por meio da fotografia, se configura em uma oportunidade para a prática educativa na educação infantil, pela qual professoras e professores podem aprender a "abrir os olhos à escuta" da dinâmica dialógica, que transcende o uso da língua, para perscrutar as ações das crianças à construção de suas culturas infantis.

Palavras-chave: Educação Infantil; Dialogia; Prática Educativa; Culturas Infantis; Fotografia.

\section{Enunciation and responsive attitude in interactive pro- cesses: building dialogues in Early Childhood Education}

Abstract: This article discusses the problem of enunciation and responsive attitude in adult-child relationship in the dialogical dynamics of early childhood education. For that establishes dialogue between authors of the Bakhtin Circle, about language to the children's understanding in the context of early childhood education and Childhood Studies by a perspective that involves the relationship between peers, especially the notion of interpretive reproduction and the concept of social order instituting, for the construction of children's cultures by children. Under the premise of educational practices that depart the interactions and games as educative situations privileged to observe the children's cultures, proposes an exploratory study on dialogical dynamics in a class of Pre, a municipal school in Curitiba, evidenced at moments processes interactive stemming from a proposal put forward by movement teacher, for which responsive attitudes of children suggest manifestations of their cultures children. These moments recorded by the researcher through photography, are revisited by observing the images to the interpretation of peer relationships and related perceptions of experience recollected by the researcher on the responsive attitudes of children. Stands out of this study to observe the children do in their interactions and games, through photography, is configured into an opportunity for educative practice in early childhood education, by which teachers can learn how to "open their eyes to listen to" dialogical dynamic that transcends the use of language, to peer into the actions of children to constructing their children's cultures.

Keywords: Childhood Education; Dialogy; Educational Practice; Children Cultures; Photography. 


\section{Educação infantil: infância, linguagem e cultura infantil}

O contexto da educação infantil se caracteriza tanto pelas peculiaridades das crianças em cada idade, por suas formas expressivas e de interação com o mundo, como também pela condição delas enquanto sujeitos pertencentes a uma categoria do tipo geracional que é a infância (SARMENTO, 2008). Podemos dizer que sendo sujeitos inseridos em um contexto histórico, social e cultural, as crianças constroem o sentido de pertencimento ao seu lugar na medida em que se relacionam com outros sujeitos e com o meio, o que se dá também por meio da linguagem (KRAMER, 2003).

Nesse âmbito, os estudos sobre a infância e a linguagem constituem campo profícuo para a interlocução de diferentes áreas entre elas a Linguística, a Pedagogia, a Psicologia, a Sociologia e a Filosofia. Solange Jobim e Souza (1994) e Sonia Kramer (2003; 2007) trazem para essa discussão autores como Bakhtin [e Volochínov], Vygotsky e Benjamin iluminando o campo da Educação. Segundo Souza (1994) há uma complementaridade fecunda no diálogo entre esses autores cujo ponto essencial consiste em "a linguagem como espaço de recuperação do sujeito como ser histórico e social.” (SOUZA, 1994, p. 93). Seguindo essa perspectiva, sob conceitos da dialogia, da autoria pela subjetividade implícita ao sujeito e da experiência, parece especialmente interessante a contribuição desses estudos sobre a linguagem à compreensão da infância na contemporaneidade, não só do século XX como nos dias atuais e, principalmente, no que tange o contexto da educação infantil.

Ampliando ainda esse espectro para pensar as culturas infantis, principalmente a partir da década de 1990, estudos da Sociologia da Infância têm composto referências importantes para a caracterização do universo infantil. Especialmente em relação à experiência educacional com crianças pequenas1, William Corsaro (2011) estuda culturas de pares produzidas e compartilhadas pela interação presencial e apresenta a noção de reprodução interpretativa ${ }^{2}$ como a própria ação da criança sobre a cultura; e Manuela Ferreira (2004) que se volta também a observar as crianças em contextos educativos, sob o conceito de ordem social instituinte, na construção de suas culturas infantis.

A ordem social instituinte (FERREIRA, 2004) e a reprodução interpretativa na cultura de pares (CORSARO, 2011), representam elementos que contribuem para pensar uma perspectiva sobre as culturas infantis na relação entre pares, a fim de olhar e interpretar os modos específicos de Qualifico como crianças pequenas os sujeitos que compõem a faixa etária da educação infantil.

2 O conceito de reprodução interpretativa denota a participação e criação das crianças na apropriação das informações do mundo adulto, daquilo que vivenciam na sociedade e na cultura, recriando e não simplesmente internalizando o que lhes é transmitido (CORSARO, 20 I I). 
as crianças ordenarem suas aprendizagens no coletivo infantil. Sendo as interações e a brincadeira, eixos da proposta pedagógica tal como instituem as Diretrizes Curriculares Nacionais para a Educação Infantil (BRASIL, 2009), as práticas educativas que partem desses eixos conformam situações educativas privilegiadas para observar as culturas infantis. Pois, os momentos derivados de interações e brincadeiras constituem oportunidades para a apropriação e troca cultural entre crianças por meio de suas ações compartilhadas.

Partindo dessa premissa, se faz necessário distinguir o entendimento das culturas infantis como arcabouço de conhecimentos que circulam entre as crianças, com os quais estas concretizam suas capacidades expressivas e exploratórias, uma vez que se compreenda, que, "as crianças nas suas interacções com os pares e com os adultos, estabelecem processos comunicativos configuradores de seus mundos de vida.” (SARMENTO, 2002). Nesse sentido, as crianças manifestam suas culturas infantis por meio das relações entre pares e as desenvolvem no espaço-ambiente ${ }^{3}$ da Instituição de Educação Infantil, o que sugere a ideia de que a relação entre pares pode ser constituidora de culturas de pares nesse contexto. A cultura de pares, assim, configura um modo de relação entre crianças, que se caracteriza por se constituir de elementos específicos e definidores do ser criança e que estão relacionados a partir de regras próprias ao universo infantil, as quais geram códigos de convivência e tipos de funcionamento atrelados ao entendimento e às ações dos sujeitos envolvidos (CORSARO, 2011).

Contudo, ainda nesse contexto educativo o(a) professor(a) como sujeito representante da cultura adulta apresenta a tradição para as crianças e media suas apropriações inserindo-as nos modos da vivência social. Tendo em vista a perspectiva das crianças, parece que a apropriação cultural por elas se dá de forma dual, por meio da integração da ordem institucional adulta, por vezes, imposta, e da ordem social instituinte (FERREIRA, 2004) construída coletivamente pelas crianças com seus pares. O que se pode constatar nos processos de integração social das crianças que "refletem dentro da instituição a força das estruturas sociais que as influenciam e a das ações que coletiva ou individualmente marcam a sua diferença.” (FERREIRA, 2004, p. 57).

Pode-se ainda considerar que no contexto educativo, as situações educativas vivenciadas pe-

3 Acerca desse conceito me remeto às contribuições de Lina Iglesias Forneiro ( 1998 ) que destaca no âmbito da educação infantil a ideia do espaço como a estrutura física e o ambiente como o conjunto do espaço e das relações que acontecem nele, envolvendo os sujeitos e os elementos materiais que o compõe. Ver em: VIEIRA. Curitiba: 20 I I. Disponível em: <http://educere.bruc.com.br/CD20 I I/pdf/4538_3347.pdf>. Acesso em: 24/04/2013. 
las crianças representam o lugar da experiência, as quais são propiciadas como oportunidades para elas. No entanto, ao ser subtraída da criança a possibilidade de exercer a experiência por si, a pobreza ocupará esse lugar (BENJAMIN, 1986). E por compreender que a criança é sujeito constituído na e pela cultura, é que se enaltece a sua relação com outros sujeitos e com os objetos na apropriação, elaboração, construção de referências e produtos da sua curiosidade, conhecimento e capacidade criativa. Sem que se incorra na infantilização como concepção da criança enquanto um devir do adulto, mas tal como defende Kramer (2007, p. 272),

uma concepção que reconhece o que é específico da infância - seu poder de imaginação, fantasia, criação -, mas entende as crianças como cidadãs, pessoas que produzem cultura e são nela produzidas, que possuem um olhar crítico que vira do avesso a ordem das coisas, subvertendo essa ordem.

$\mathrm{Na}$ educação infantil ${ }^{4}$, o(a) professor(a) ocupa o lugar de um outro especialmente significativo e determinante para as relações que as crianças estabelecem nesse contexto. A imperícia que marca os primeiros anos de vida das crianças impõe uma relação de dependência dos adultos, sobretudo, no atendimento às suas necessidades básicas e, consequentemente, de suas demandas comunicativas. É nesse âmbito que o adulto-professor(a), sujeito privilegiado da cultura em condição de promover a inserção das crianças no mundo social, apresenta para elas as primeiras referências de uma vivência coletiva institucionalizada, na qual a linguagem se constitui elemento delimitador da ação, uma vez que potencializa significados por meio da fala. Aqui reside o problema da enunciação em processos interativos responsivos na relação entre adulto e crianças, presente na dinâmica dialógica desses sujeitos na educação infantil.

Para abordá-lo farei uso da interlocução com os autores do Círculo de Bakhtin ${ }^{5}$, na tentativa de iluminar o contexto da educação infantil e enxergar para além da composição didática, nos entremeios das relações pré-estabelecidas pelo discurso pedagógico, os sujeitos que interagem e a sua relação com a linguagem.

\footnotetext{
4 No Brasil, o atendimento às crianças na faixa etária da educação infantil é realizado em diferentes tipos de instituições, nas redes públicas em Centros Municipais de Educação Infantil (CMEls) ou Escolas Municipais de Educação Infantil e de Ensino Fundamental, no âmbito privado, em Centro de Educação Infantil ou Escolas de Educação Infantil. Assim, o termo educação infantil será adotado para representar tais instituições.

5 Ao considerar especialmente as obras "Marxismo e Filosofia da Linguagem" (VOLOCHÍNOV, 20 I 2) destaca-se que apesar desta ter sido divulgada como sendo de Bakhtin, a mesma tem a contribuição mais explícita de Voloshinov, por isso opto pela autoria deste na referência à obra e "A estética da criação verbal" (BAKHTIN, 20 I I) escrita pelo próprio Bakhtin.
} 
Aproximações bakhtinianas com o contexto da educação infantil

Primeiramente é importante destacar da trama dialógica, o uso da língua entre os sujeitos de uma mesma comunidade linguística, na qual tais indivíduos estão integrados na unicidade da situação social imediata, sob "uma relação de pessoa para pessoa sobre um terreno bem-definido." (VOLOCHÍNOV, 2012, p. 72). Isso significa dizer que, para haver troca linguística entre esses sujeitos precisa existir uma condição que propicie a comunicação por meio da fala, como fato de linguagem. A língua e seus signos, compartilhados na troca social, constituem a concretude que viabiliza a interação verbal, que se dá pela ação imediata de sujeitos inseridos em um meio social comum sob as determinações do seu contexto de vida. No âmbito da educação infantil, desde os gestos, o olhar e a tonicidade da fala, a dinâmica interacional ligada à língua é comandada pelo adulto, que dirige a palavra às crianças como aquele que nomeia e atribui significados a serem apropriados por elas enquanto um bem coletivo. Seja por serem iniciantes na vivência social ou pela sua condição de aprendizes da língua, as crianças necessitam da interação com sujeitos mais experientes da cultura para serem inseridas nela.

Contudo, a palavra é uma unidade da língua pronunciada nunca de forma neutra, mas, "carregada de um conteúdo ou de um sentido ideológico ou vivencial. É assim que compreendemos as palavras e somente reagimos àquelas que despertam em nós ressonâncias ideológicas ou concernentes à vida." (VOLOCHÍNOV, 2012, p. 99. grifo do autor).

No entanto, esse conteúdo ideológico que preenche a palavra de um sentido próprio ao sujeito que fala, não é absorvido pelo ouvinte de forma plástica, senão interpretado por este a partir de seus referentes anteriores, ou seja, pela experiência com aquela palavra que denota a presença de outros interlocutores no universo do entendimento do sujeito ouvinte.

Aqui está precisamente a contribuição mais valiosa à incursão da dialogia bakhtiniana para a compreensão da interação verbal como campo de constituição do sujeito na relação com outros sujeitos, em sua condição social e histórica. Tal se dá sob a égide do movimento entre aquele que fala e um outro que escuta sem perder a perspectiva de que no determinado momento do diálogo estão ambos situados em um intervalo da sua inter-relação com outros que os antecederam. Estes outros povoam a compreensão do sujeito sobre as coisas do mundo e as próprias relações que estão na eminência de acontecer nessa interlocução premente na interação verbal e que dirigem sua ação 
enquanto ouvinte. Essa máxima bakhtiniana de que somos povoados por outros, ao mesmo tempo em que evidencia o enredamento como condição social, traz uma perspectiva original à questão da autoria, como bem observou Souza (1994) ao se referir à compreensão do papel do outro na interação verbal e na comunicação estética.

A questão da autoria é, por assim dizer, um tema essencial na sua concepção dialógica da linguagem. Para Bakhtin, a palavra não pertence ao falante unicamente. É certo, diz ele, que o autor (falante) tem seus direitos inalienáveis em relação à palavra, mas o ouvinte também está presente de algum modo, assim como todas as vozes que antecederam aquele ato de fala ressoam na palavra do autor. (SOUZA, 1994, p. 100).

A palavra entendida, não meramente como unidade da língua, ainda que se reconheça essa qualidade que a distingue em sua natureza, mas, como potencial da enunciação, unidade da comunicação discursiva ${ }^{6}$, prenhe de significados, os quais são compartilhados no processo de interação verbal na inter-relação dos sujeitos de um contexto determinado.

Na realidade toda palavra comporta duas faces. Ela é determinada tanto pelo fato de que procede de alguém, como pelo fato de que se dirige para alguém. Ela constitui justamente o produto da interação do locutor e do ouvinte. Toda palavra serve de expressão a um em relação ao outro. Através da palavra defino-me em relação ao outro, isto é, em última análise em relação à coletividade. A palavra é uma espécie de ponte lançada entre mim e os outros. Se ela se apoia sobre mim numa extremidade, na outra apoia-se sobre o meu interlocutor. A palavra é o território comum do locutor e do interlocutor. (VOLOCHÍNOV, 2012, p. 117. grifo do autor).

$\mathrm{Na}$ educação infantil, parece peculiar à condição da faixa etária que um locutor, sujeito da cultura adulta, apresente a palavra para a criança como enunciado e sua apropriação por esta corresponda à tentativa de domínio da língua para estabelecer a comunicação com outros sujeitos. O que não limita a possibilidade de ampliação do repertório linguístico dos sujeitos-crianças por meio de suas capacidades expressivas. Assim, parece pertinente considerar que a palavra se constitua uma primeira referência de enunciado a ser apropriado pela criança, mesmo que se componha em uma oração completa em termos de sentido e estrutura gramatical.

Nessa perspectiva, se pode pensar a experiência de apropriação da língua pela criança na educação infantil em situações diversas, nas quais as interações verbais ocorrem a partir de enun-

6 A comunicação discursiva se apresenta para Bakhtin como uma unidade que envolve sujeitos num âmbito dialógico cuja interação ocorre por meio do discurso. 
ciações pronunciadas pelo(a) professor(a), revestidas de concepções e expectativas, as quais são dirigidas às crianças sob certa intencionalidade educativa, para a qual elas se manifestam de forma expressiva. Sobre esse aspecto ressalta-se que "o centro organizador de toda enunciação, de toda expressão, não é interior, mas exterior: está situado no meio social que envolve o indivíduo.” (VOLOCHÍNOV, 2012, p. 125). Tal referência remete-se ao fato de que, ao mesmo tempo em que o locutor e o ouvinte estão conectados por uma situação social mais imediata, também são determinados por um meio social mais amplo, que representa a sua gama de interlocutores, os outros que povoam sua enunciação.

Por isso, se de um lado o(a) professor(a) está imbuído(a) de referências e concepções acerca da enunciação pronunciada, as crianças também lançam mão de suas próprias referências para interpretá-la e relacioná-la ao seu arsenal de experiências e proceder de forma responsiva. Nisso reside a compreensão de que a interação verbal, como comunicação discursiva, pressupõe uma corrente de enunciados, em que cada um destes constitui a sua real unidade. Uma vez entendido que, "o discurso sempre está fundido em forma de enunciado pertencente a um determinado sujeito do discurso, e fora dessa forma não pode existir.” (BAKHTIN, 2011, p. 274), pois, tais sujeitos são situados histórica e socialmente, em um contexto compartilhado.

Nessa corrente de enunciados, cada unidade da comunicação discursiva está definida pelo limite do discurso do outro, configurando uma alternância dos sujeitos do discurso (BAKHTIN, 2011), os falantes da língua. Esse é o movimento concreto no "diálogo real, em que se alternam as enunciações dos interlocutores (parceiros do diálogo), aqui denominadas réplicas." (BAKHTIN, 2011, p. 275).

Vale ressaltar que na educação infantil, mesmo que haja no discurso do(a) professor(a) elementos que indiquem uma suposta dialogia, nem sempre há espaço presumido para a interlocução, uma vez que a ação do adulto se expresse por uma conotação diretiva em relação as crianças para que estas correspondam à sua expectativa. Ainda assim, em acordo com uma perspectiva sobre as cultura infantis na relação entre pares (CORSARO; 2011), as crianças agem sobre o enunciado que o professor pronuncia de forma responsiva, ou seja, por meio da réplica, uma vez que tal interação se caracterize pela comunicação discursiva. Pois, "cada réplica, por mais breve e fragmentária que seja, possui uma conclusibilidade específica ao exprimir certa posição do falante que suscita resposta, em 
relação à qual se pode assumir uma posição responsiva." (BAKHTIN, 2011, p. 275).

Nesse contexto, a criança como ouvinte capta o sentido da enunciação e se apropria das palavras que lhe ressoam, refrata aquilo que lhe é possível compreender e se expressa conferindo à elas um significado não do enunciado, nem do seu conteúdo interior, mas, mediante a aproximação de ambos, uma outra coisa, uma nova possibilidade interpretativa experimentada como ação responsiva ao enunciado.

Essa ação como linguagem, ou seja, unidade da comunicação discursiva pode ser expressa por enunciados das mais diversas formas. Invariavelmente, a criança utiliza a imaginação como dimensão criativa e dela lança mão para responder aos estímulos do meio em que está inserida. No entanto, tal ação responsiva não ocorre alheia à sua experiência, como algo totalmente novo, pelo contrário, segundo Vigostski (2009, p.22) "a atividade criadora da imaginação depende diretamente da riqueza e da diversidade da experiência anterior da pessoa, porque essa experiência constitui material com que se criam as construções da fantasia.”.

Frente a isso, se pode reconhecer na réplica da criança a sua interpretação sobre o enunciado do outro. Portanto, não é possível desconsiderar a sua condição como participante potencial em quaisquer situações educativas, enquanto sujeito de discurso. Sobretudo, se é na relação com o outro que o sujeito se constitui humano, por meio da linguagem e da vivência da cultura compartilhada e construída em sua experiência cotidiana, parece relevante considerar a dialogia na prática educativa da educação infantil.

Imbuída desse olhar me propus a um estudo ${ }^{7}$ sobre a relação entre adulto e crianças no espaço-ambiente da educação infantil, sob a premissa das práticas educativas que partem das interações e das brincadeiras, como situações educativas privilegiadas para observar a construção de culturas infantis.

Incursões no Círculo de Bakhtin à percepção das culturas infantis

Nesse estudo me propus identificar a dinâmica dialógica e relacionar elementos da enunciação e das atitudes responsiva das crianças dela decorrentes, em momentos de processos interativos de uma situação educativa, registrada e observada por meio da fotografia.

7 Esse estudo fez parte do processo de construção da metodologia de pesquisa do projeto de doutorado Imagens da experiência educativa de professores da educação infantil no espaço-ambiente do Proinfância, e se relaciona, especialmente, à disciplina Leituras Bakhtinianas ministrada pelo Prof. Dr Gilberto de Castro do Programa de Pós-Graduação em Educação da Universidade Federal do Paraná, no ano de 2013. 
Tal situação educativa documentada foi proposta pela professora de movimento, especialis$\operatorname{ta}^{8}$ e também colega ${ }^{9}$ do doutorado, a qual configurou foco do registro fotográfico que realizei como estratégia de registro primário ${ }^{10}$ para o estudo exploratório, cuja finalidade consistiu delinear aspectos à construção de uma metodologia de pesquisa baseada na captura de momentos para posterior observação.

Desafiada pelas leituras bakhtinianas me instiguei a adentrar no referido contexto de educação infantil com uma predisposição ao estranhamento no sentido pleno do termo, ou seja, aberta às surpresas que a situação educativa a ser fotografada poderia deflagrar. Essa intencionalidade como exercício da pesquisa se deve também à preocupação com a desconstrução de pressupostos cristalizados acerca da prática educativa na educação infantil e das características comuns às crianças dessa faixa etária, concernentes à minha experiência profissional. Com isso não quero dizer que todo o conhecimento que baseia a minha visão sobre esse contexto deva ser descartado, mas, para poder enxergar para além do que vejo, me propus a, desconhecendo, lançar-me pela aventura de perceber no outro uma emanação.

Munida apenas de informações obtidas com a professora previamente acerca do grupo de crianças e da proposta que seria encaminhada, realizei o registro fotográfico da situação educativa vivenciada pelas crianças, sob uma inspiração documental. Dessa perspectiva interpreto que a fotografia expressa um ato de criação sob a escolha de um sujeito em um instante dos tempos, por seu testemunho (KOSSOY, 1989), pois, ainda que como ato de criação toda fotografia corresponda a uma produção, também indica seu caráter documental que tange ao tempo histórico, vivido pelo fotógrafo, bem como e do sujeito ou objeto fotografado. O sujeito-fotógrafo inserido em uma sociedade, com uma determinada experiência e enredado em sua contemporaneidade, captura em uma fração de segundo do tempo fotográfico uma versão da realidade sob sua perspectiva de mundo.

registro visual documenta, por outro lado, a própria atitude do fotógrafo diante da realidade; seu estado de espírito e sua ideologia acabam transparecendo em suas imagens, particularmente naquelas que realiza para si mesmo enquanto forma de expressão pessoal. (KOSSOY, 1989, p. 27).

8 A professora especialista é formada em Educação Física, concursada no município de Curitiba, exercendo essa função na educação infantil.

9 Como colegas realizamos uma atividade proposta pela disciplina Interação Social, componente do PPGE-UFPR, a qual gerou este artigo.

10 O registro fotográfico foi definido como registro primário da situação observada uma vez que a partir dele foi estruturada a descrição da observação. 
À luz do que destaca Kossoy (1989) visto que o fotógrafo é um sujeito implicado em um tempo e um espaço, sua ideologia, entendida como o aporte cultural que se lhe agrega no decurso de sua experiência de vida, exerce influência na perspectiva sobre o que fotografa. Deste modo, me situo enquanto fotógrafa ${ }^{11}$ que testemunhou a realidade capturada por um olhar que recorta e elege referentes que lhe são significativos.

Com o propósito de experimentar o uso da fotografia como instrumento metodológico na pesquisa em educação, a partir do registro fotográfico realizado, me voltei às imagens a fim de observar as cenas capturadas, as quais pude descrever, bem como, rememorar minhas percepções em cuja interpretação relaciono elementos da enunciação e das atitudes responsivas das crianças. Assim, proponho a abordagem fotográfica como meio e instrumento para delinear o contexto educativo e a situação educativa, respectivamente.

O campo de estudo, que corresponde a uma escola de ensino fundamental, da Rede Municipal de Ensino de Curitiba, situada no bairro Cidade Industrial, se caracteriza por uma comunidade do entorno da escola que se constituiu de famílias oriundas de favelas e áreas de invasão que ali se estabeleceram no final de década de 1960, atualmente, formada por população de baixo poder aquisitivo, configurando comerciantes, trabalhadores e, por vezes, desempregados ${ }^{12}$.

Destaco que na escola o foco para esse estudo consistiu em acompanhar a proposta realizada pela professora de movimento em uma turma de Pré, composta por 25 crianças entre 4 e 5 anos de idade, durante um período de 50 minutos.

A fim de delinear o contexto educativo onde acontece a investigação do estudo proposto, inicio com a apresentação da sala da turma do Pré por meio das imagens (fotos 1, 2, 3 e 4) desse contexto educativo antes da professora apresentar a sua proposta ao grupo de crianças.

\footnotetext{
II Realizo a atividade de fotógrafa desde o ano de 1993, quando comecei a fotografar a dança, o cotidiano da escola, bem como, situações educativas com finalidade didática.
} 


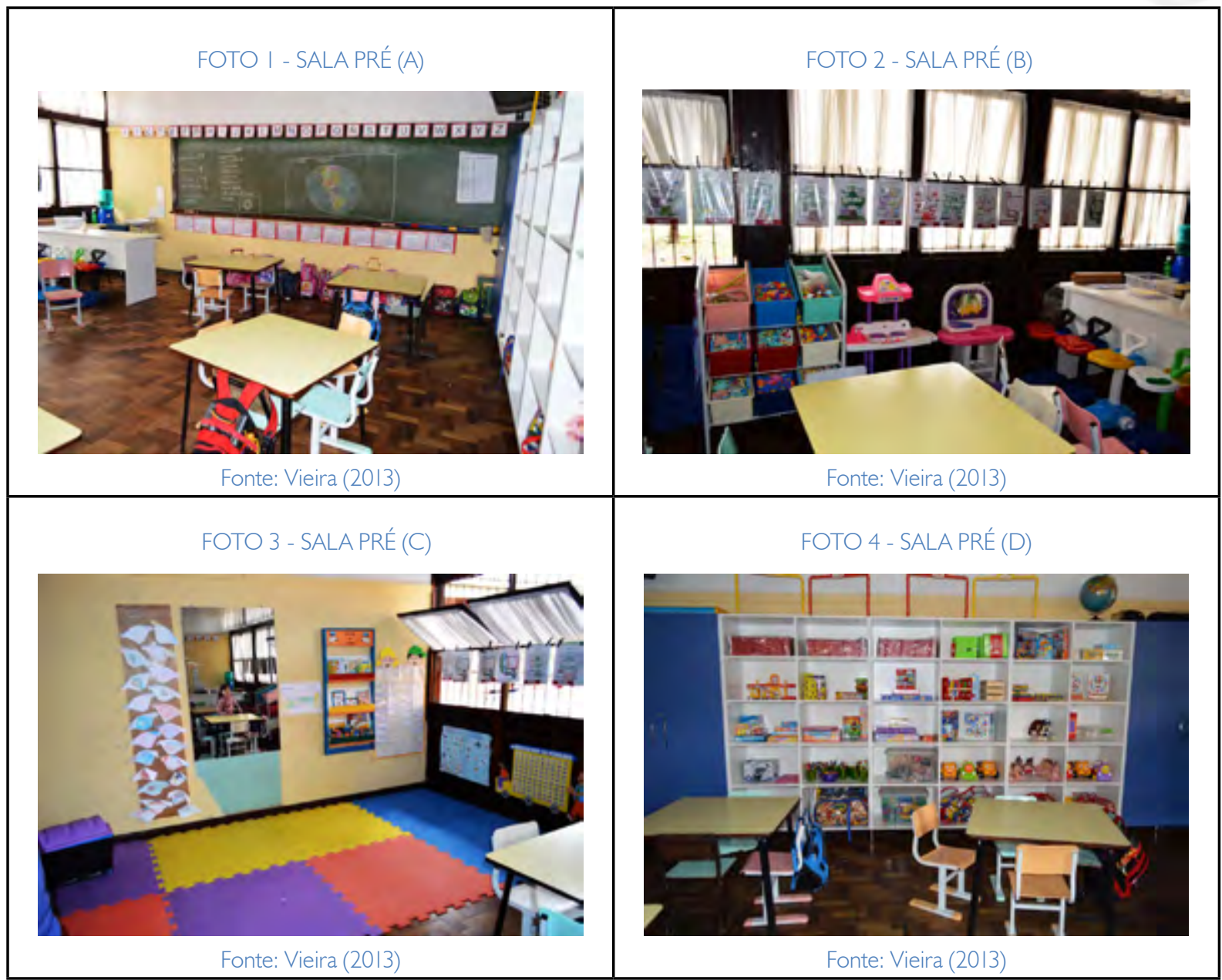

Denoto na composição da sala a diversificação de elementos e disposição de mobiliário que: ora remetem a práticas escolarizadoras ${ }^{13}$ com alfabeto fixado acima do quadro negro, textos escritos que sugerem a cópia, a mesa da professora ${ }^{14}$ voltada para o centro da sala; ora aludem a práticas comuns ao universo da educação infantil, tal como se evidencia na foto 3 pelo tapete, que sugere um lugar de uso coletivo pelo grupo, um expositor com livros disponíveis às crianças, os materiais didáticos interativos bem como o espelho à altura delas, ou como nas fotos 2 e 4 , que mostram os brinquedos acessíveis para elas.

A situação educativa, registrada e observada, ocorreu nessa sala durante uma prática de movimento ${ }^{15}$ para a qual a configuração desse contexto educativo não foi modificada durante a sua execução. O objetivo da proposta da professora era propiciar às crianças oportunidade de brincar

13 Tendo em vista que esta turma do Pré se situa em uma Escola Municipal, a presença de elementos que implicam práticas escolarizadoras próprias à alfabetização pode revelar a penetração de objetivos do ensino fundamental na educação infantil. Ainda assim, a composição da sala parece ampliar as possibilidades interativas às crianças sobrepondo tais elementos.

I4 Essa denominação será adotada a partir de agora tendo em vista que nessa turma de Pré a regente é uma professora.

I5 Destaca-se que no município de Curitiba a prática de movimento se constitui como um fazer pedagógico que parte do entendimento da linguagem corporal como componente da Educação Infantil. Ver em: Curitiba. Caderno pedagógico: movimento. Secretaria Municipal de Educação/ Prefeitura de Curitiba, 2009. 
com fantoches e bonecos que representavam diferentes etnias, sob a intencionalidade de abordar as relações étnico-raciais no cotidiano da educação infantil, o que seria tratado posteriormente em uma roda de conversa. Ressalto, contudo, que para o estudo realizado interessou destacar da situação educativa, apenas os elementos da comunicação discursiva, a saber: a enunciação realizada pela professora de movimento e as atitudes responsivas das crianças como decorrências constituidoras dos processos interativos desencadeados.

Assim, apresento o aspecto da referida situação educativa em que a professora encaminha a proposta com o grupo de crianças, sob a descrição dessa vivência mediante o registro fotográfico:

... a professora mostrou uma caixa - com fantoches e dois bonecos -, perguntou ao grupo o que eles achavam que tinha ali, ao que responderam "brinquedo"; então ela levantou e disse: "Turma, vocês podem escolher um brinquedo dessa caixa para brincar, mas não vale pegar 'outros brinquedos' da sala, só o que tem na caixa”; todos foram ao mesmo tempo pegar seu brinquedo; imediatamente iniciou a tomada do espaço pelas crianças em posse de seus fantoches e dos dois bonecos-bebês. (VIEIRA, 20I3. Registro de Observação)

$\mathrm{Na}$ enunciação pronunciada pela professora às crianças, destaco o sentido da ação de escolher um brinquedo da caixa para brincar, mas não vale pegar 'outros brinquedos' da sala, só o que tem na caixa, que interpreto como finalidade atender ao objetivo da proposta relacionado às questões étnico-raciais, uma vez que os bonecos e fantoches representavam uma diversidade de etnias. No entanto, nessa determinação, em que a professora enfatiza uma delimitação para a atitude responsiva das crianças, ao propor a elas o brincar com determinados brinquedos, compõe à estrutura do seu enunciado uma ideia em relação à ação das crianças que em sua essência parece incompatível com um significado plausível às culturas infantis e denotativo à palavra brincar, se entendido que para a criança tudo pode ser brinquedo no brincar.

Depreendo disso que a perspectiva de culturas infantis decorrentes da reprodução interpretativa que Corsaro (2011) atribui às ações das crianças, constitui parâmetro para observar a relação entre elas e o adulto frente à comunicação discursiva. Com o que problematizo no enunciado da professora a restrição ao brincar quanto à: definição dos fantoches e dos bonecos como brinquedos para serem escolhidos pelas crianças; e determinação de outros brinquedos, disponíveis na sala como evidenciam as fotos 2, 3 e 4, a não serem escolhidos por elas. Tal restrição me parece indicar uma dissonância de entendimentos entre a professora e as crianças relativa aos significados do brin- 
car e do que consiste brinquedo, tendo em vista a possibilidade de as crianças lançarem mão de seus modos de brincar nesse contexto educativo, que apresenta vários elementos acessíveis a elas.

Se qualquer objeto pode ser brinquedo, como seria não poder eleger algo como brinquedo para brincar? Seria possível à criança ignorar a latência de seu desejo por um objeto como brinquedo no momento da brincadeira? Seria possível à professora observar a percepção das crianças em relação ao seu objetivo, considerando seus modos próprios de apropriação manifestados por suas culturas infantis?

Isso posto observo as imagens a seguir como momentos do brincar proposto, as quais sugerem atitudes responsivas das crianças mediante o enunciado da professora.

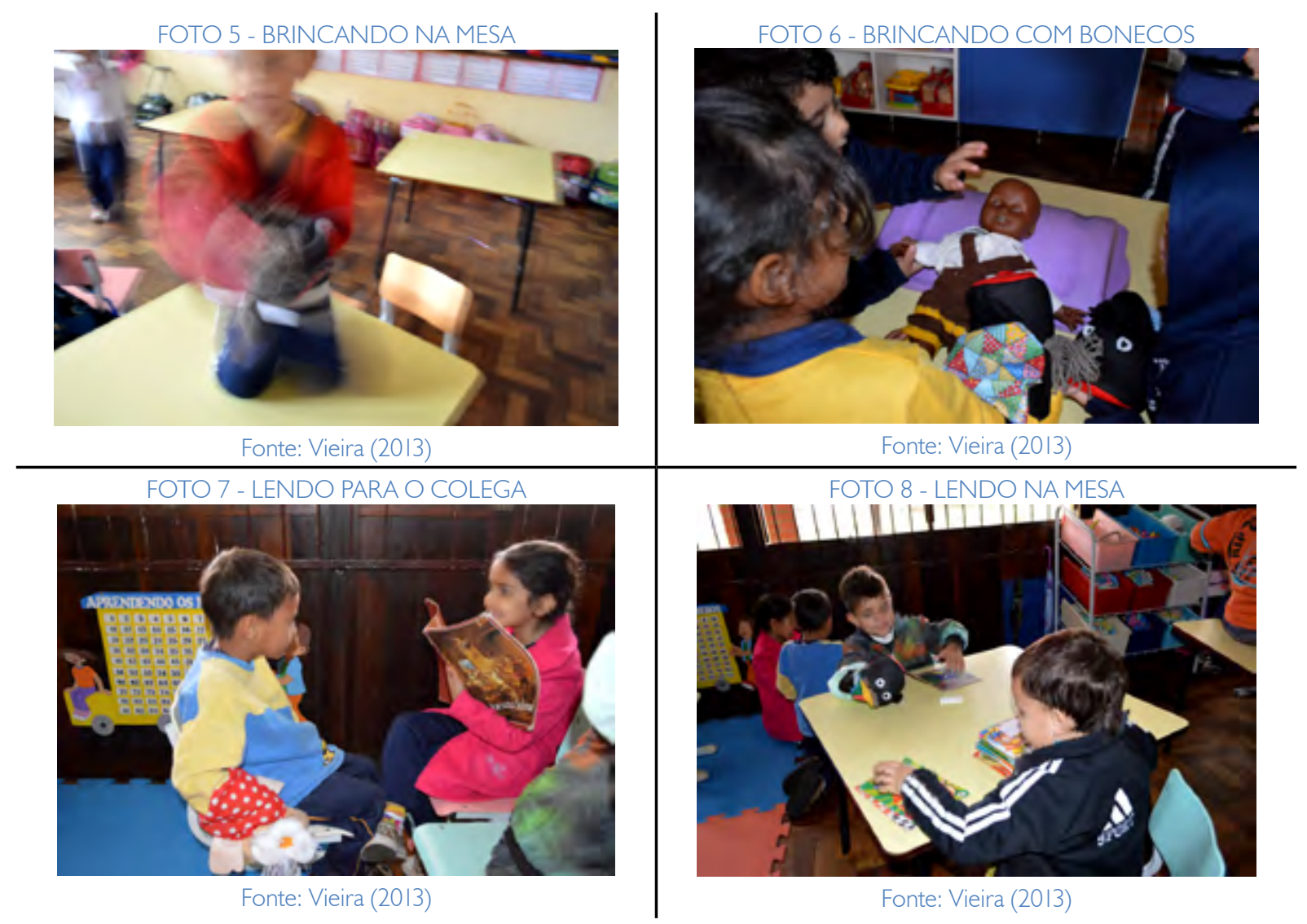

Nessas imagens (foto 5, 6,7 e 8) percebo indícios de que as crianças ocupam todo o espaço da sala e também transgridem a ordem comum do cotidiano quando brincam, o que parece referir ao conceito da ordem social instituinte (FERREIRA, 2004) com o que estabelecem suas relações nesse contexto educativo. Com destaque às imagens (fotos 5, 6 e 8 ) em que aparece a mesa: mobiliário que geralmente tem função definida pelas atividades de rotina na instituição de educação infantil, tais como, de apoio para a execução de tarefas, de suporte para o ritual da alimentação ou 
para a conformação de grupos na realização de algo em comum; ao ser apropriada pelas crianças como objeto na brincadeira, a mesa lhes possibilita experimentar outras perspectivas e planos como meio para a manifestação de suas culturas infantis, em que utilizam o corpo e sua capacidade de movimentação para transgredir. Mesmo que nesse caso não haja uma infração relacionada ao enunciado pronunciado pela professora, que destacou as palavras brincar e brinquedo, ao subir em cima da mesa (foto 5) um menino a transforma em objeto do brincar e transgride a ordem de utilizar somente os brinquedos da caixa para tal. Assim, me parece que o corpo e a capacidade de movimentação constituem elementos de comunicação nessa dinâmica dialógica, em que a criança interpreta a possibilidade de brincar por meio dessa apropriação da mesa como elemento disponível para realizar sua brincadeira.

Ressalto que essa percepção acerca da apropriação pela criança da mesa como elemento, decorre de minhas reflexões sobre a prática educativa na organização do espaço pedagógico e a constituição do eu infantil, cujo contexto educativo se constrói sob as relações que a criança estabelece com outros sujeitos - adultos e crianças - e com os materiais nele presentes, como espaço-ambiente (VIEIRA, 2011). Dessas reflexões passei a problematizar a prática educativa no espaço-ambiente, pela interdependência de relações que ultrapassam as paredes, os objetos, o mobiliário, os pátios, os adultos, os companheiros de grupo e os lugares que frequentam.

Me detenho aos modos de apropriação pelas crianças de outros elementos do espaço-ambiente, para além daqueles determinados pela professora, e observo um pequeno grupo (foto 6) que realiza a exploração de um boneco apoiado na mesa em uma posição que parece reconhecida e recriada pelas crianças a partir de vivências que compartilham, por sua própria experiência de ser criança ou por presenciarem ações de cuidados com outras crianças, o que sugere a reprodução interpretativa. Enquanto o boneco-bebê permanece sob a guarda e o cuidado do grupo a tampa de uma caixa serve de apoio, simulando um travesseiro, sua utilização parece importante para a representação do vivido. Rememoro uma cumplicidade percebida nesse momento, cuja enlevação das crianças parece transmutar um mundo imaginado a partir de significados originários de sua própria experiência relacional e que constituem seu repertório afetivo. Visualizo uma situação de faz de conta, pela qual ocorre uma forma de comunicação tangível, por meio de gestos como modos de cuidar desde a perspectiva das crianças e de impressões que elas têm sobre esse momento que recriam no 
espaço-ambiente da educação infantil.

Me parece que nisso reside o estabelecimento de diálogos que prescindem do uso da língua, em que os corpos das crianças se mostram predominantemente expressivos mediante a percepção do vivido, das sensações que a própria experiência se lhes imprimiu, como uma dança de movimentos que constituem um ritual de relações. Nessa dinâmica dialógica, as atitudes responsivas das crianças transcendem a enunciação da professora, por meio da brincadeira, na qual confluem repertórios e possibilidades derivadas da reprodução interpretativa como expressão de suas culturas infantis.

Seguindo o que meu olhar captura, surge o livro (fotos 7 e 8), enquanto objeto da cultura e não determinado pela professora como um brinquedo, por ser eleito pelas crianças sua inserção na brincadeira poderia ser considerada também uma transgressão. Penso na apropriação pelas crianças do objeto-livro como uma manifestação da ordem social instituinte à construção de suas culturas infantis.

Nesse sentido, destaco as fotos 7 e 8 , semelhantes em relação ao objeto-livro utilizado pelas crianças para brincar ou manipular, ao se compor na brincadeira com o fantoche, o brinquedo do enunciado. Porém, as duas fotos revelam diferentes modos de apropriação do livro como elemento mediador na situação de brincar de leitor. A foto 7 evidencia uma interação entre sujeitos, enquanto a menina representa o ato de ler e o menino detém em sua mão direita um fantoche, o interesse pela história parece suplantar a ação com o brinquedo-fantoche como ordem instituída. Vislumbro nessa cena uma relação entre pares que, ao transgredir o que havia sido estabelecido pela professora, as crianças expressam um modo próprio de suas culturas infantis pela apropriação livre dos objetos. Observo mais detidamente essa imagem (foto 7) e penso na apropriação do livro como elemento da brincadeira, em que a linguagem aparece como meio de comunicação sobre algo conhecido, a interlocução leitor-ouvinte, e ainda, a interpretação da história tendo em vista a expressão da menina ao emitir uma mensagem de modo incisivo. Me parece que a dialogia se revela aqui pela expressão corporal e também pela representação de papéis, que denota a brincadeira de faz de conta comum nessa faixa etária, pela qual as crianças comunicam significados relativos aos atos de ler e de ouvir, interpretados por elas em seu modo de agir.

Já a foto 8 apresenta no plano de fundo um menino manipulando um livro com a mão 
esquerda enquanto apoia a mão direita com o fantoche na mesa, concomitantemente no primeiro plano da imagem outro menino manipula vários livros, um de cada vez, sem nenhum fantoche. São dois meninos compondo uma cena em que a interação em evidência se dá com o objeto, pois ambos parecem alheios entre si. Submersos nessa manipulação como forma de interação com o objeto-livro, tal me sugere que a utilização da linguagem ocorre como reafirmação ou representação do papel de leitor. Não há na imagem uma comunicação aparente entre as crianças, mas, uma diante da outra, sua composição insinua que nesse espaço, os modos próprios a elas que compõem suas culturas infantis, podem ser compartilhados por uma forma de dialogia marcada por gestos, passíveis de imitação pela captura do olhar do outro.

Observando as imagens derivadas da situação educativa $(5,6,7$ e 8) proposta pela professora, não me furto de pensar na prática educativa como o que conforma oportunidades às crianças ampliarem seus repertórios em suas brincadeiras, e das culturas infantis como formas próprias à elas de transgredirem quaisquer restrições ao brincar, de ressignificarem objetos, experimentarem seus usos, se apropriarem de modos culturais por sua própria experiência.

Assim, instigada pelo que meu olhar fotográfico capturou nos momentos vivenciados pelas crianças, por meio das minhas interpretações pude relacionar percepções decorrentes da situação educativa, rememorada na observação da imagem. Desse modo, as imagens me deram pistas para interpretar possibilidades responsivas das crianças ao enunciado da professora e nessa inter-relação pude estabelecer parâmetros à compreensão de dialogias na educação infantil.

Com isso, compreendo que a fotografia constitui um instrumento plausível para pensar a dialogia entre práticas educativas e culturas infantis.

\section{Apontamentos e considerações}

Os exemplos de atitudes responsivas das crianças em relação ao enunciado da professora de movimento, evidenciam que elas são criativas e capazes de diversificar possibilidades expressivas. Tanto pelo fato do brincar sugerir uma amplitude de ações, como pelo fato de que cada criança ou grupo de crianças, ao ser-lhes dada a oportunidade de expressar-se o fazem segundo suas demandas e necessidades, as quais estão relacionadas com suas experiências e repertórios de vida.

Isso me sugere que na educação infantil, a dialogia não pode ser apenas relacionada à capa- 
cidade expressiva da língua, tal como observado, parece necessário considerar outras dimensões que contemplem as peculiaridades da idade, como a dimensão espacial, por meio do corpo e movimento - capacidade de movimentação na sala -, a dimensão relacional pela representação da afetividade jogo simbólico ou faz de conta - e a dimensão cultural com a dramatização de um papel socialmente construído - interlocução entre leitor e ouvinte. Essas seriam possibilidades investigativas que esse estudo sobre a dialogia na educação infantil me instiga a pensar e que interpreto como oportunidades à reflexão da experiência educativa.

Como estudo exploratório, o registro fotográfico e a observação descrita da situação educativa com as crianças do Pré, propiciou uma análise a partir dos conceitos bakhtinianos da dialogia, do enunciado e da atitude responsiva, em uma perspectiva sobre as culturas infantis construídas pelas crianças nas relações entre pares, por meio da reprodução interpretativa (CORSARO, 2011) e da ordem social instituinte (FERREIRA, 2004). Com isso, me volto à concepção de infância de Sonia Kramer, especialmente por destacar o modo da criança ver as coisas, que vira o mundo do avesso, como um modo vê-la, pois "esse modo de ver as crianças pode ensinar não só a compreender as crianças, mas também a ver o mundo do ponto de vista da criança. Pode nos ajudar a aprender com elas." (KRAMER, 2007, p. 272).

No entanto, por vezes, à revelia do potencial que as crianças têm como sujeitos capazes de interpretar à sua própria maneira o mundo, à revelia dos significados que elas constroem sobre suas vivências, à revelia do que sentem, do que lhes importa, do sentido que suas ações têm para sua experiência, os adultos insistem em controlar, planejar e projetar suas percepções.

Observar o que as crianças realizam em suas brincadeiras e interações pode, de fato, configurar um caminho para professoras e professores aprenderem a "abrir os olhos à escuta" da dinâmica dialógica, que transcende o uso da língua, para perscrutar as ações das crianças à construção de suas culturas infantis.

E, finalmente, como estudo metodológico a vivência de fotografar para observar, também possibilitou delinear aspectos pertinentes ao uso da fotografia como instrumento de investigação. Tanto pela possibilidade do registro fotográfico à produção de dados, como pela observação da imagem enquanto rememoração do vivido, uma nova oportunidade de encontro do olhar de pesquisadora com o objeto de estudo. 
Mais ainda, penso na fotografia como possibilidade para as professoras e os professores aprenderem a olhar e a perscrutar as ações das crianças à constituição de suas culturas infantis, por ser um instrumento que lhes devolve a cena, em tempo, configura uma oportunidade para pensar sobre sua prática educativa.

\section{REFERÊNCIAS}

BAKHTIN, M. Estética da criaçáo verbal. 6.ed. São Paulo: WMF Martins Fontes, 2011.

BENJAMIN, W. Magia e técnica, arte e política. 2. ed. São Paulo: Brasiliense, 1986.

FERREIRA, M. Do "avesso" do brincar ou... as relaçóes entre pares, as rotinas da cultura infantil e a construção da(s) ordem(ens) social(ais) instituinte(s) das crianças no jardim-de-infância. In: SARMENTO, M.; CERISARA, A. B. Crianças e miúdos: perspectivas sociopedagógicas da infância e educação. Lisboa: Edições ASA, 2004.

FORNEIRO, L. I. A organização dos espaços na educação infantil. In: ZABALZA, M. A. Qualidade em Educaçáo Infantil. Porto Alegre: Artmed, 1998, p. 229 - 281.

CORSARO, W. A. Sociologia da Infância. 2. ed. Porto Alegre: Artmed, 2011.

KRAMER, S.; LEITE, M. I. L. Infância: fios e desafios da pesquisa. 7. ed. Campinas, SP: Papirus, 2003, p. 13 - 38.

Infância e educaçáo infantil. 6. ed. Campinas, SP: 2007, p. 269 - 280.

KOSSOY, B. Fotografia e história. São Paulo: Ática, 1989.

SARMENTO, M. J. Imaginários e Culturas da infância. 2002. Disponível em < http://titosena.faed.udesc.br/Arquivos/Artigos_infancia/Cultura\%20na\%20Infancia.pdf> Acesso em: 19 dez. 2015.

São Paulo: Vozes, 2008.

; GOUVEA, M. C. S. Estudos da Infância: educação e práticas sociais.

SOUZA, S. J. Infância e linguagem: Bakhtin, Vygotsky e Benjamin. Campinas, SP: Papirus, 1994.

VIEIRA. A constituição do eu e o espaço pedagógico na educação infantil: formação para a docência. Curitiba: 2011. Disponível em: <http://educere.bruc.com.br/CD2011/pdf/4538_3347. pdf $>$. Acesso em: 24/04/2013.

VIGOTSKI, L. S. Imaginaçáo e criação na infância. São Paulo: Ática, 2009.

VOLOCHÍNOV, V. N. Marxismo e filosofia da linguagem. 13. ed. São Paulo: Hucitec, 2012. 